\title{
HYBRIDS FOR AUTOMOTIVE APPLICATIONS
}

\author{
DIETRICH BERGFRIED \\ Robert Bosch GmbH, Dept, K8/EHS, P.O. Box 42, D-7410 Reutlingen 1, Germany
}

(Received June 5, 1981; in final form June 26, 1982)

The design aspects of automotive hybrids are discussed in general and illustrated by two specific examples, a thick film module used in the electronic fuel injection controller and a solid state ignition module. The environmental test conditions for the automotive environment are summarized, and it is shown how these conditions influence the hybrid design.

\section{INTRODUCTION}

Electronic control circuits are finding increasing use in engine control functions. The main driving forces behind this development are the need for better fuel economy, reduction of maintenance costs, better engine performance and the imposition of more stringent exhaust emission standards. The experience of the industry over the last 10 years has shown, that the success of automotive electronics depends primarily on two critical issues:

- the cost effectiveness, i.e. the cost/benefit ratio of the solution

- the reliability issue.

The continued growth and increasing use of complex electronics will therefore depend on how well these two issues can be solved.

Thick film hybrids offer several features which make them particularly attractive for this application. Among them are:

- Special packaging and versatile interconnection capabilities suitable to withstand the temperature, shock and vibration stresses of the automotive environment under the hood

- High reliability because of low thermal resistance and a minimum number of interconnections.

- Excellent manufacturing quality through automated manufacturing techniques

- High performance because of functional trimming to tight tolerances and good thermal tracking

- Cost effective combination of control and power circuits in one fully tested component.

\section{HYBRID PRODUCT DEFINITION}

Before a decision is made to develop a hybrid for a particular application it should be carefully evaluated if the hybrid solution offers any of the technology related advantages listed above. If the circuit can be built using standard components and the only advantage of a hybrid is its smaller size then it should be checked very thoroughly whether the hybrid is competitive. However, if a hybrid is the best choice in view of its technological features, hybrid considerations should be introduced already at the system design level to 
achieve the most cost effective solution. If this is not possible and the interfaces between various system components are fixed, at least the circuit design should be tailored to hybrid technology. A one to one translation from a discrete circuit to a hybrid, even if possible, does not result in the most cost effective solution. The design process should not be started before a complete specification has been worked out. Ideally this specification should define target values and ultimate limits where possible, rather than firm tolerances, to allow some flexibility and to avoid a too elaborate design. Just as important as the circuit definition is the reliability issue. The reliability of a system depends to a large extent on the stresses of the application. These electrical, mechanical, and environmental stresses have to be well understood and considered in every step of the development cycle to achieve a reliable product.

The environment for automotive electronics is well documented. ${ }^{1,2}$ The severity of the environmental stress conditions depends on the location of the electronic system within the vehicle. Complex electronics such as fuel injection controllers, are usually mounted in the better protected area inside the passenger compartment or the trunk while simpler units such as ignition modules or voltage regulators are mounted under the hood. These components have to withstand the extended temperature range $\left(-40\right.$ to $\left.+125^{\circ} \mathrm{C}\right)$, rapid temperature changes $(100 \mathrm{~K} / \mathrm{min})$ and the salt spray, humidity and chemical environment of the engine compartment.

From measurements on test vehicles simplified laboratory test programs have been developed. Table I shows such a typical test program. These tests are performed in the

TABLE I

Standard environmental accelerated stress tests (acc. to DIN 40 046)

\begin{tabular}{|c|c|c|c|c|}
\hline & & $\begin{array}{l}\text { Pass. compartment } \\
\text { and trunk }\end{array}$ & Under the hood & $\begin{array}{l}\text { Duration } \\
\text { in hours }[\mathrm{h}] \\
\text { cycles }[\mathrm{c}] \\
\text { or days }[\mathrm{d}]\end{array}$ \\
\hline 1. & Temperature operating & & & \\
\hline 1.1 & $\begin{array}{l}\text { Short term cycling } \\
\text { (thermal shock) }\end{array}$ & $-40^{\circ} \rightarrow+85^{\circ} \mathrm{C}$ & $-40^{\circ} \rightarrow+125^{\circ} \mathrm{C}$ & $500 \mathrm{c}$ \\
\hline 1.2 & $\begin{array}{l}\text { Long term cycling } \\
\text { (thermal cycling) }\end{array}$ & $-40^{\circ} \rightarrow+85^{\circ} \mathrm{C}$ & $-40^{\circ} \rightarrow+125^{\circ} \mathrm{C}$ & $1000 \mathrm{c}$ \\
\hline 1.3 & High temp. operating & $+85^{\circ} \mathrm{C}$ & $+125^{\circ} \mathrm{C}$ & $1000 \mathrm{~h}$ \\
\hline 1.4 & Low temp. operating & $-40^{\circ} \mathrm{C}$ & $-40^{\circ} \mathrm{C}$ & $250 \mathrm{~h}$ \\
\hline 2. & Humidity operating & & & \\
\hline 2.1 & Tropical climate & $23^{\circ} / 83 \% \leftrightarrow 40^{\circ} / 93 \%$ & $23^{\circ} / 83 \% \leftrightarrow 55^{\circ} / 93 \%$ & $21 \mathrm{~d}$ \\
\hline 3. & Saltspray, chemicals & & & \\
\hline 3.1 & $5 \% \mathrm{NaCl} 35^{\circ} \mathrm{C}$ & in housing & $14 \mathrm{~V}$ bias & $96 \mathrm{~h}$ \\
\hline 3.2 & $\begin{array}{l}\text { Oil, Gasoline, } \mathrm{SO}_{2} \\
\text { in sequence }\end{array}$ & - & $14 \mathrm{~V}$ bias & $24 \mathrm{~h}$ \\
\hline 4. & Mechanical stress & & & \\
\hline 4.1 & Shock & $20 \mathrm{~g}$ & $20 \mathrm{~g}$ & $10 \mathrm{c}$ \\
\hline 4.2 & Vibration-random & $5 \mathrm{~g}$ & $5 \mathrm{~g}$ & $24 \mathrm{~h}$ \\
\hline 4.3 & Vibration $20-300 \mathrm{~Hz}$ & $1,5 \mathrm{~g}$ & $4 \mathrm{~g}$ & $9 \mathrm{~h}$ \\
\hline
\end{tabular}


controlled laboratory environment for the purpose of identifying defects and critical or marginal areas of the design. They are part of a qualification program which also includes vehicle and long term durability tests were several of these conditions are superimposed simultaneously or sequentially. Conditions such as shown in Table I have to be factored into the design considerations and any material or process used has to be qualified for these conditions.

The hybrids discussed in the next sections illustrate by two examples, how these conditions can influence the design of such devices.

A product qualification test program consists of a combination of these tests in conjunction with electrical overstress depending on the special application and the technology used.

\section{HYBRID MODULES FOR THE FUEL INJECTION CONTROLLER}

The electronic fuel injection system L-Jetronic was introduced in production vehicles in 1973. Over the years more functions were added to improve the system's performance for different engine operating conditions. ${ }^{3}$ Since it was not possible to enlarge the housing because of space limitations in the car it was decided to develop three hybrids for the basic functional blocks of the control unit and to use a modular concept. One of these hybrids is shown in Figure 1.

The design goals for these hybrids were set as follows:

- Use standard modules and functional laser trimming to cover all parameter variations required by the different engines for the different customers.

- The cost goal of the modules was set below the cost of the equivalent discrete circuits.

- Reliability to be at least equal to the existing circuits.

Standard thick film resistors proved to be stable enough as long as the size and shape of the trim resistors was chosen according to the required trim sensitivity and stability of the

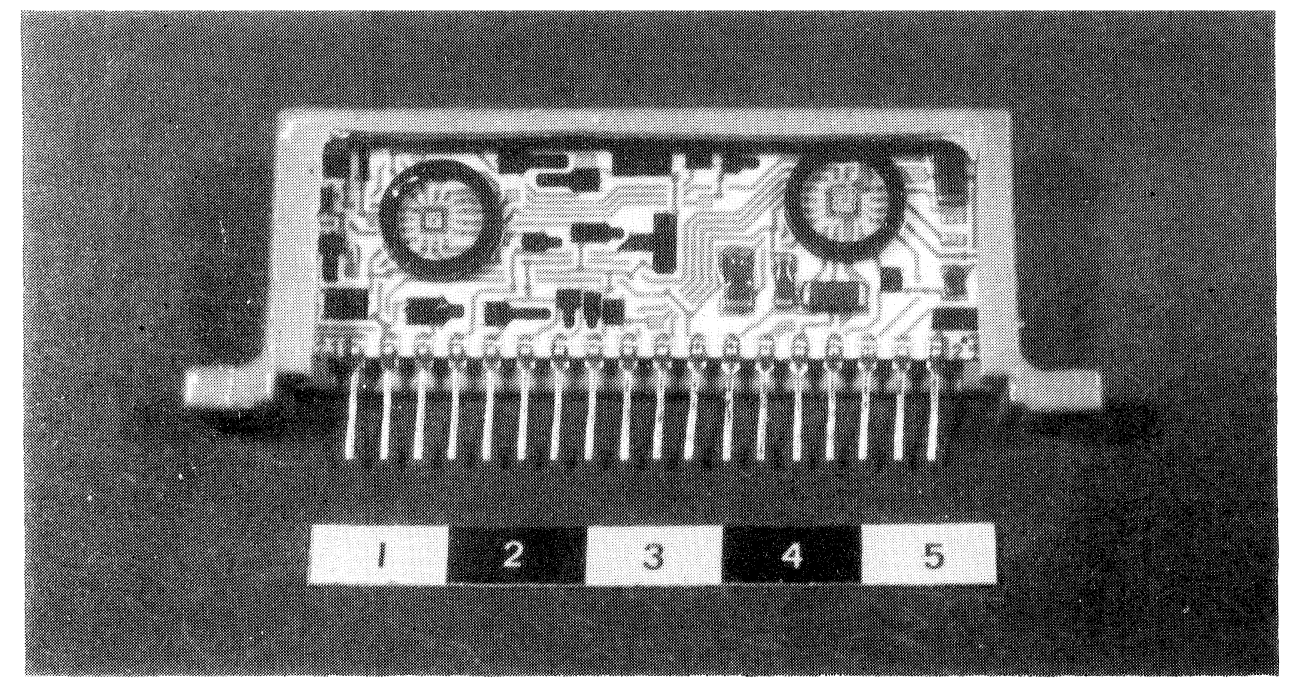


particular function. Among the different assembly methods tested to attach chip capacitors the screen printed conductive epoxy performed best in the temperature cycling tests. Since the same epoxy was used for die bonding it had to be assured that no corrosion would damage the IC metallization in the non-hermetic package.

The reliability of the wire bonds was considered the most critical area of the design in view of the temperature cycling requirement. Extensive tests were therefore carried out to evaluate different thick film pastes for ultrasonic aluminium wire bonding in regard to bond strength, aged adhesion, paste surface roughness and sensitivity to changes of machine parameters. $50 \mu \mathrm{m} \mathrm{Al}$ bonding wire and a thick-film gold metallization were selected to achieve the desired high bond strength (typically $\geqslant 30 \mathrm{cN}$ ). After the wire bonding operation a laminated paper ring is placed around the IC and filled with a very soft silicon gel.

This encapsulation exerts almost no forces on the wire bonds in the operating temperature range. The method proved to be cost effective and very reliable in all temperature cycling and humidity tests.

The modules are functionally laser trimmed according to customer requirements. After lead frame soldering they are inserted in coloured plastic shells and coated with silicon rubber which covers the complete substrate (passivation against silver migration). The plastic shell is necessary as a protection against handling damage during final testing of the module and in the assembly (and repair) of the control unit.

A total of 655 hybrids from different pilot lots were tested in accordance with the test conditions of Table I to qualify the design. Only one IC failure was recorded in the temperature cycling test. Based on the available information the failure rate per hybrid is currently less than $0.01 \%$ in the warranty period, which corresponds to $\geqslant 10^{-8} / \mathrm{h}$.

The manufacturing process is presently being mechanized. The manual wire bonding is converted to automatic aluminium wire bonding. Automated feed systems using $50.8 \mathrm{x}$ $50.8 \mathrm{~mm}$ substrates have been installed on all manufacturing steps including the functional laser trimming.

\section{HYBRID IGNITION MODULES}

Solid state ignition systems have been widely used in the United States since 1975. These systems are gaining increased popularity among the European automobile manufacturers. Figure 2 shows such an ignition module for a magnetic sensor.

The basic functions performed by such modules are listed below:

- Coil current regulation to obtain high and constant spark energy under all operating conditions

- Dwell angle control to minimize the power dissipation in the power transistor

- "On-time cut off" to avoid continuous maximum current operation of the module with the ignition turned on but the engine not running

- Protection against false triggering due to line voltage transients

- Collector voltage clamping to protect the power transistor against "second breakdown".

A hybrid is particularly attractive for this application because it offers a cost effective way to combine the required power and control circuits with the necessary flexibility regarding connector geometries required by different customers. Such an ignition module can be broken down into three subassemblies, the power assembly, the thick-film hybrid and the housing assembly. Each of the sections has its unique problems. 


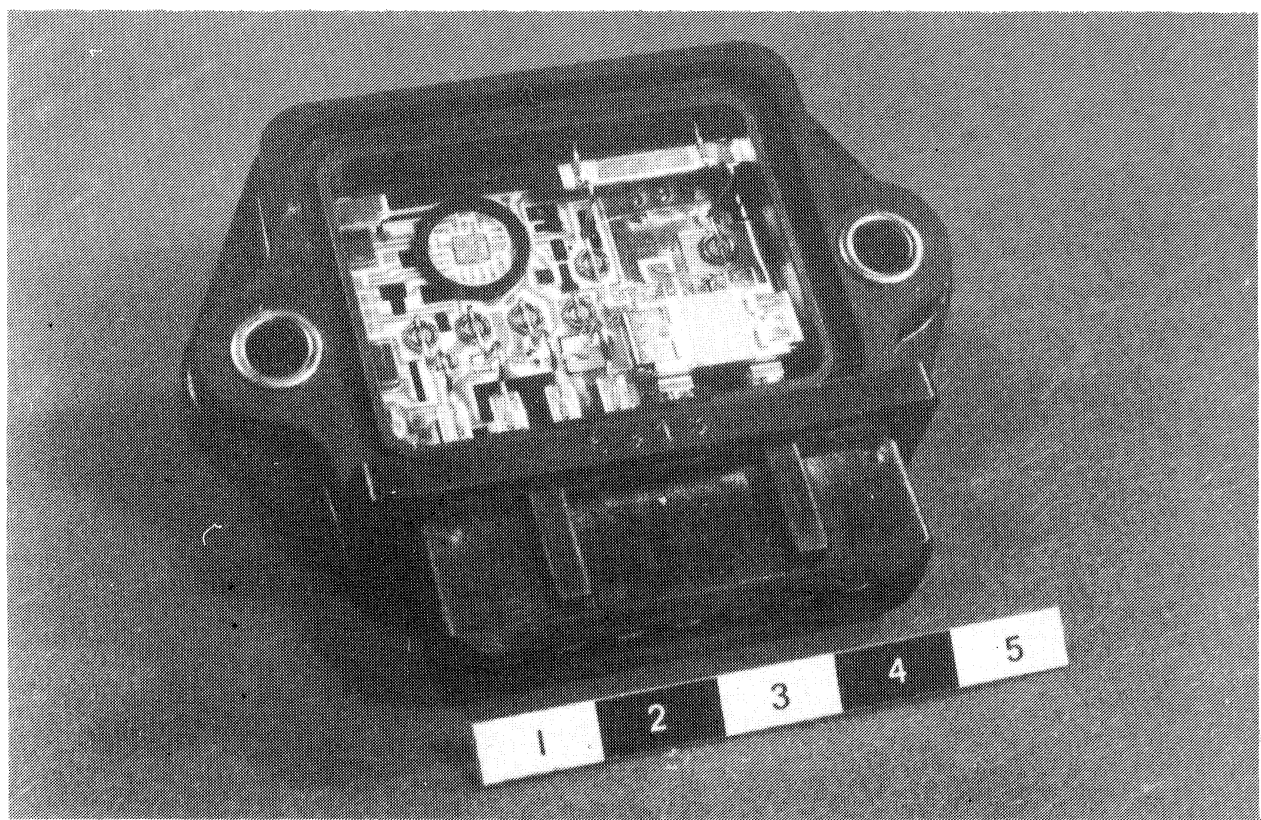

FIGURE 2 Hybrid transistorized ignition

The power transistor has to regulate pulse currents of up to $8 \mathrm{~A}$ at case temperatures from $-40^{\circ}$ to $+125^{\circ} \mathrm{C}$. This requires an assembly with low thermal resistance and an excellent power cycling durability. The power Darlington is soldered on a $\mathrm{BeO}$ substrate directly to the housing baseplate, wirebonded to a terminal strip and protected against contamination by a drop of silicon junction coating. The assembled Darlington is protested electrically to assure all electrical and thermal parameters. The thick-film hybrid combines all the circuitry for the control functions, among them the current sensing and the high voltage clamping. A section of the PdAg conductor serves as the current sensing resistor for the coil current control loop. For the currents of up to $8 \mathrm{~A}$ which are flowing across this path soldered metal pellets are used as welding terminals for the connecting wires to the housing.

The manufacturing process of the thick film hybrid is very similar to the process used for the fuel injection modules. The IC's are again epoxy mounted and wire bonded using $50 \mu \mathrm{m}$ aluminium wire. The main difference is the use of solder paste instead of conductive epoxy for the weld terminals. The thick film hybrids are completely pretested during functional trimming to assure a high final assembly yield.

The final assembly steps are: attaching the hybrid to the base plate, glueing of the housing and the base plate will cause substrate breakage if the adhesive used does not remain flexible over the temperature range. An epoxy filled gauze is used here. Another critical area is the seal of the semihermetic housing. Gross leaks cause sufficient corrosion inside the housing to make the modules fail the salt spray test. The design of the metal to plastic glue joint, the materials and the process have to be worked out carefully. Extensive testing and characterization during pilot production and production startup was necessary to improve critical areas in the manufacturing and testing operation through failure analysis and corrective action.

The field reliability of these modules in production since 1978 has been better than $0.2 \%$ based on the available information from failure reports. 


\section{CONCLUSION}

Hybrids should be used in applications where their inherent advantages can be utilized. In such cases the optimal approach is to start from scratch and to define the system around the hybrid to as great an extent as possible. During the development, the performance, testing, reliability and process capability aspects have to be considered at each step of the development cycle to obtain a quality product. The design has to be tailored to the environmental stress conditions as illustrated by the two examples.

\section{REFERENCES}

1 J.N. Thielmann, Reliability Considerations in the Use of Integrated Circuit Packaging Systems in Automotive Environment. Society of Automotive Engineers, SAE Paper Nr. 770229 (1977).

2 O.T. McCarter, Environmental Guidelines for the Designer of Automotive Electronic Components, Society of Automotive Engineers, SAE Paper Nr. 740017 (1974).

3 H. Scholl, Elektronische Benzineinspritzung mit Steuerung durch Luftmenge und Motordrehzahl, MTZ 34, S 99-105, (Franksche Verlagshandlung, Stuttgart 1973), German. 

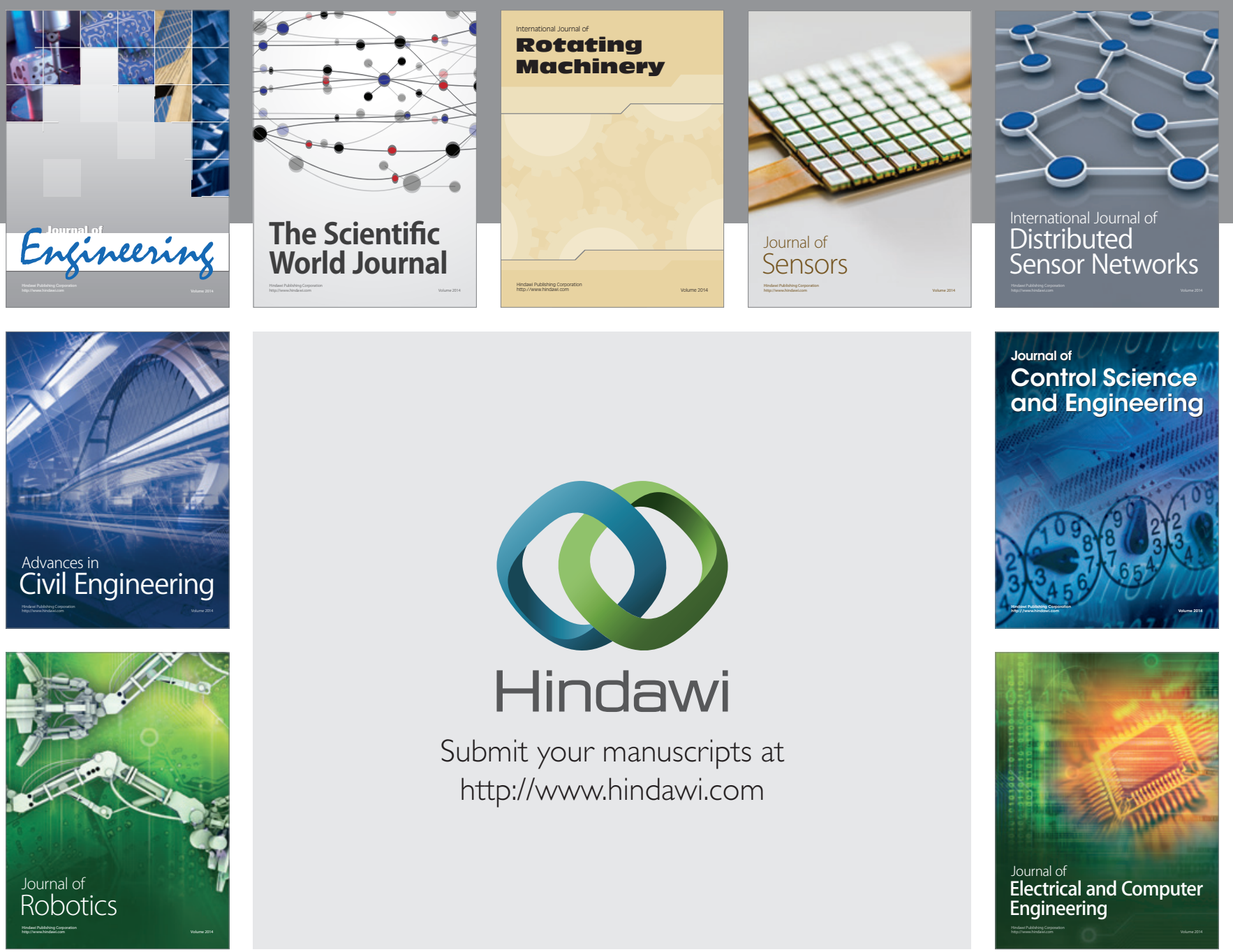

Submit your manuscripts at

http://www.hindawi.com
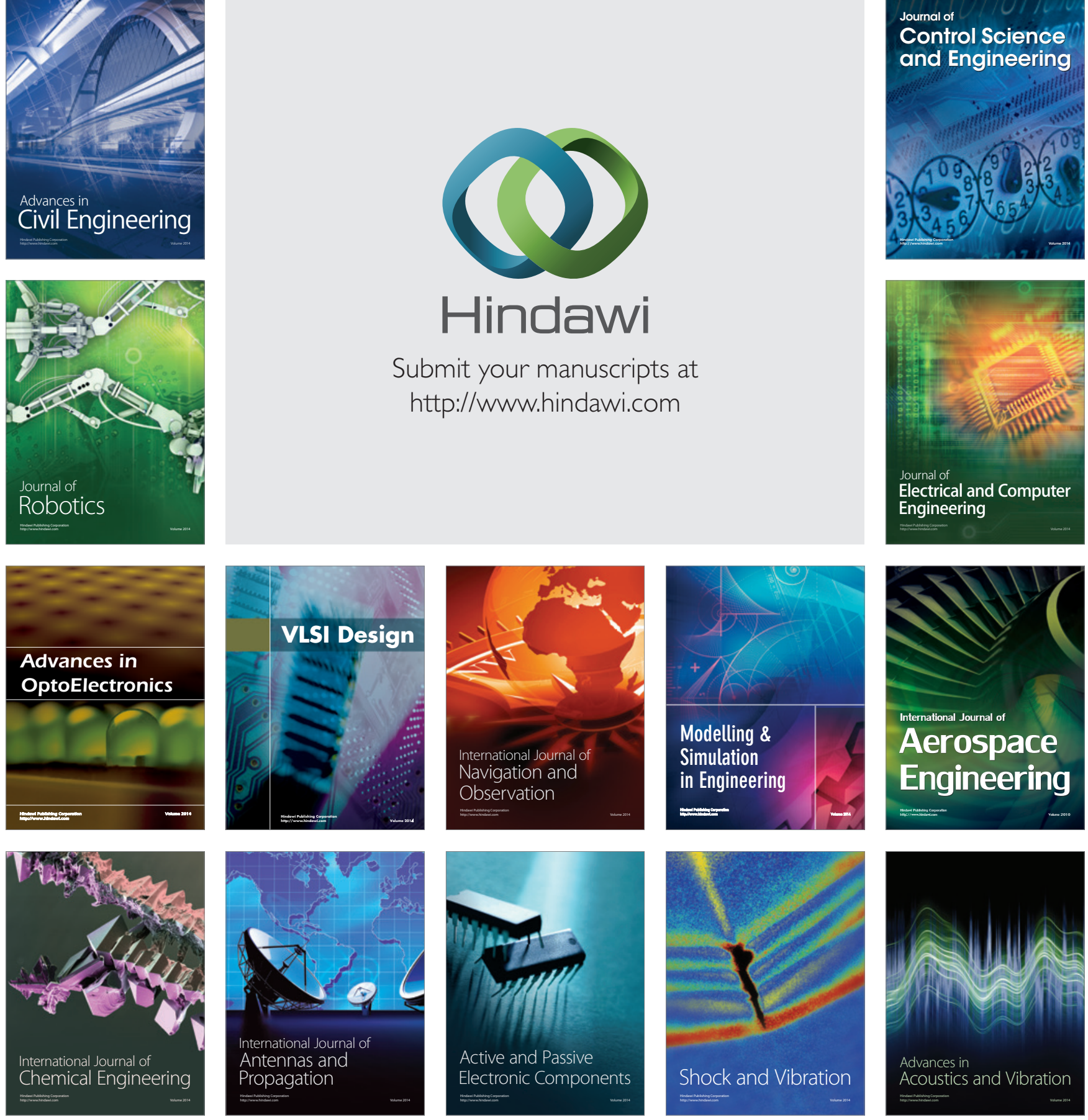